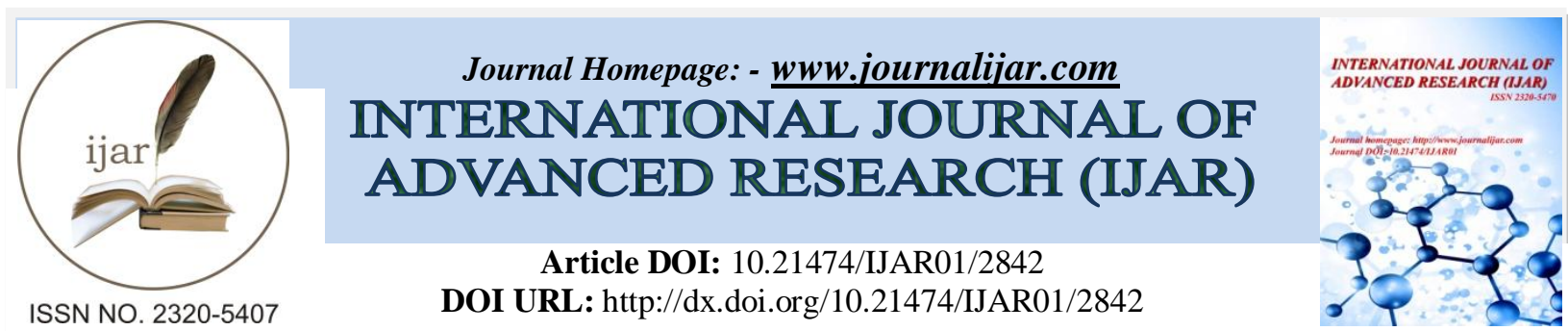

RESEARCH ARTICLE

\title{
ASSESSMENT LEVEL OF AWARENESS TOWARD RADIATION EXPOSURE RISK AMONG COMMUNITY IN MAKKAH CITY.
}

Bader Ali yahya asiri, Basim Abdularzzak Felmban, Abdul aziz Jamaan Alzahrani, Awdah Abdulrahman Alkhathami, Mohammed Ali Alzubaidi, Bader Ibrahim Asiri, Ahmed Abulhuda Olfat, Saeed Yahya Asiri and Amjad Turki fakieh.

\section{Manuscript Info}

Manuscript History

Received: 18 November 2016

Final Accepted: 19 December 2016

Published: January 2017

\section{Abstract}

Background: Radiological procedures are being used much more these days. Patients must be given sufficient information, in a way that they canunderstand, to be able to make the right decisions about their care.

Objectives: To examine health beliefs and assessment level of awareness toward radiation exposure risk among the general population of Makkah, Saudi Arabia.

Methods: A cross sectional analytical questionnaire based study among the general population of Makkah City.

Results: A total of 360 subjects answered the questionnaires. The mean age were 36 years, ranged from 16 to 70 and $45.2 \%$ females and $43.7 \%$ male respondents.Of these, $67 \%$ had attended college, 5\% had postgraduate degree, $23.5 \%$ had completed high school, and 3.1\%hadbasic school. The majority of participants had high level of monthly income (38\%). The majority of subjects included in the research were $(59.6 \%)$ married and $(51.3 \%)$ were unemployed.

Most subjects (338)had poor knowledge about hazards of exposure to radiation and there was no association between the knowledge and demographics of participants except for education as the higher the levels of education, the more significant association with good knowledge.

Conclusion: The knowledge of radiation exposure hazards was poor among the studied population.Also, education significantly impacts the knowledge of radiation risks thus there is a need for providing the patients with necessary information to improve theirradiation awareness.

Copy Right, IJAR, 2016,. All rights reserved.

\section{Introduction:-}

\section{Background:}

Ionizing radiation in medical imaging is one of the powerful diagnostic tools in medicine. Radiation which is applied in radiology departments has hazardous effects on biological systems ${ }^{(1)}$. Ionizing radiation is a broad, complicated, and often misunderstood topic. Exposure to ionizing radiation is associated with both acute and chronic disease states, especially as the radiation dose increases ${ }^{(2-4)}$. 
Overexposure to ionizing radiation is a significant factor causing biological diseases such as various cancers, lens opacity, erythema, and genetic mutations ${ }^{(5)}$. Children are particularly susceptible to ionizing radiation and, because of their young age, may be more likely to experience delayed manifestations of ionizing radiation exposure. Nevertheless, individuals are constantly exposed to ionizing radiation from a variety of sources: naturally occurring, medical imaging, and other human-made. Studies indicate a difference in both risk perception and knowledge of actual sources of ionizing radiation between the general public and radiation experts ${ }^{(6-8)}$.

There is no threshold level of radiation exposure below which it could be said with certainty that cancer or genetic effects will not occur. Doubling the radiation dose doubles the probability that a cancer or genetic effect would occur. Epidemiological studies on populations exposed to radiation showed a significant increase of cancer risk at doses above $100 \mathrm{mSv} / \mathrm{yr}^{(8)}$. Studies have suggested that the general public is not concerned about exposure to ionizing radiation from medical procedures because of a widespread notion that healthcare professionals have received extensive training in principles of radiation and are competent in minimizing risk ${ }^{(9,10)}$.

Our study was designed to examine health beliefs and assessment level of awareness toward radiation exposure risk among community in Makkah City and applies the Health Belief Model to determine barriers.

\section{Rationale:-}

Over the past two decades there was an increase in demand for radiologic imaging procedures in health care services to help in medical design making.Ionizing radiation can cause serious effects on the hematopoietic system, digestive system, skin, testicles, ovaries, central nervous system, and ultimately, the entire body. In Saudi Arabia, there are few studies that assessed awareness on radiation hazards among community.

\section{Literature Review:-}

Nowadays, radiological procedures are being used much more with technological advances. Those proceduresassists in thediagnosis and management of many medical conditions. Requesting imaging modalities comprise risk factor to the patients(ionizing radiation cancer-causing biological effects). Every year there is increasing in the number of patients who are in need of diagnostic radiology ${ }^{(11,12)}$, especially computed tomography $(\mathrm{CT})$ scanning. During the last few years, the doses of radiation have increased up to $40 \%$ per scan ${ }^{(13)}$.

The repeated exposure to radiation increases the possibility of getting cancer.The lowest dosage of radiation for which there is a real proof of cancer-causing is around $10-50 \mathrm{mSv}$. The regularexposure dosage for one chest radiograph taken is around $0.02 \mathrm{mSv}$, and for an abdominal CT is around $9 \mathrm{mSv}$. Theradiation from chest X-ray (CXR) is almost certainly less thanbackground radiation established in a whole year (0.01 mSvdaily).Around0.015 $\mathrm{mSv}$ is received during a three-hour airline flight ${ }^{(14)}$.

It is essential that doctors who request imaging to be well trained in determining whether diagnostic imaging isrequired, but also they need to be aware of the associated risk. It has performed in many studies that the knowledge of medicalprofessional on radiation hazards and dosage is limited ${ }^{(15,16)}$.

A study published in 2006 by the Pediatric Radiology Journal showed that about $87 \%$ of pediatricians misjudged the radiation dosage from a chest radiograph and $94 \%$ underestimated the radiation dosage from a $\mathrm{CT}{ }^{(1)}$.

Not only doctors hadinsufficient knowledge about radiation risks and dosage. In 2010, a study was performed to study the knowledge of doctors showed that half of thesenior medical students and intern doctors underestimated the radiation doses from usually requested radiologicalprocedures. Some of them incorrectly think that ultrasound (US) and magnetic resonance imaging (MRI) produce ionizing radiation ${ }^{(17)}$.

A study conducted by Karsli et al.,(2009) indicated that a significant percentage of physiciansadvice that informed consent should beobtained from patients undergoing radiological exams and the information about cancer-related risks involvedshould be provided by the radiological department ${ }^{(18)}$.

Most contributors did not talk with patients about the associated hazards of radiation. A sufficient information should be given to patients,in a way that they can understand, to be capable of making the right decisions about their care $^{(19)}$. 
Few projects are focusing on the patient's knowledge about radiation risk in the literature. Two recent studiesconfirmed that the most of patients $(74 \%)$ would consider that having their situation diagnosed with CT ismore important than disturbing about radiation and patients had insufficient knowledge about radiation protection $(15,20)$

Surprisingly, a number of articles have appeared in the literature that predict hundreds of cancers and cancersmortality per year in the U.S. and U.K. caused by ionizing radiation from medical imaging procedures. It wasestimated 100-250 deaths occur per year from cancers directly related to exposure to medical radiation in U.K ${ }^{(21)}$. InU.S, the estimated number of fatalities attributable to CT was 700-1800 during a year ${ }^{(22)}$.

Also, a recent pilot study was conducted among the general population of Makkah, Saudi Arabia, 2016 showed that education significantly affects the knowledge of radiation exposure hazards ${ }^{(23)}$.

\section{Objectives:-}

General objectives:-

To assess the level of awareness toward radiation exposure risk among community in makkah city and to identify barriers.

\section{Specific objective:-}

The goal of this study was to examine community health beliefs regarding radiation exposure risk and their perceptions related to it and evaluate the role of demographic factors in shaping beliefs about radiation and assess possible associations between demographic characteristics with the preventive behavior of interest.

\section{Methods:-}

Study design: cross sectional study.

\section{Setting and data collection:-}

This survey analysis was conducted among community population in Makkah city. A preformed self-administered questionnaire was distributed among the community population.

\section{Sample:-}

Subjects were chosen according to geographical and sex distribution. Sample size was calculated based on web-site calculator ${ }^{(24)}$ taking the total size of Makkah population $(1,249,000){ }^{(25)}$, confidence level $(95 \%)$ and margin error (5\%) to be 285 . Additional $20 \%$ was added to cover the missing data. The total sample obtained was 360.

\section{Study population:-}

The study population included were both male and female in Makkah City.

\section{Study tool:}

Preformed Self-administered questionnaire that requires information about:

1- Demographic characteristics: age, gender, education level, monthly income, marital status, and employment.

2- Knowledge assessment including 7 questions about risk factor of radiation and factors associated with long exposure to radiation. A score of 1 was given to yes and 0 otherwise. For each subject, a maximum score of 7 was calculated.A scoring system was applied to measure the respondents' knowledge towards radiation impacts. The radiation knowledge score was calculated as a continuous variable by summing the participant's number of yes answers to the questions. One point was awarded for each yes, and zero for each no or don't know, with a maximum obtainable correct score of 7 for each respondent. The knowledge score was categorized into two levels indicated by poor (0-4.5), and good (5-7).

\section{Ethical considerations:-}

An informed consent was obtained from the participants included in this research before filling the questionnaire.

\section{Statistical analysis:-}

Data were entered into the Statistical Package for Social Sciences (SPSS, version 24, SPSS, Chicago, IL, U.S.A.) and descriptive analysis conducted. The results were reported as percentage ( $95 \%$ confidence interval). 
The internal consistency was assessed using Cronbach's $\alpha$ test. The test results were for the7 statements of knowledge about radiation exposure hazard was 0.422 .

Association of respondents' characteristics with about radiation exposure hazard, was evaluated using univariate logistic regression.Results were reported showing odds ratio (OR) and 95\% confidence interval. Statistical significance was accepted at $\mathrm{p}<0.05$. The dependent variables: knowledge of radiation exposure risk $(1=$ Poor knowledge and $0=$ good knowledge). The following independent variables were included: (1) age: $\leq 20$ years, [2130 years], [31-40 years],[41-50 years], > 50 years; (2) gender: males and females; (3) level of education: low, for those who completed secondary school or less, intermediate for those who finished college degree or have bachelor degree and high for those who had postgraduate degree; (4) monthly income: low [<3000Saudi Riyal (SR)], middle [3000-10000 SR] and high [>10000 SR];(5)marital status: single and married; (6) employment: unemployed and employed.

\section{Results:-}

Demographics of the studied subjects:

The socio-demographic characteristics were shown in Table. 1.

Table 1:- Socio-Demographic Characteristics of Respondents $(\mathrm{n}=360)$

\begin{tabular}{|c|c|c|}
\hline & Frequency & Percentage (\%) \\
\hline \multicolumn{3}{|l|}{ Age (Year) } \\
\hline$<=20.00$ & 36 & $8.60 \%$ \\
\hline $21.00-30.00$ & 125 & $29.70 \%$ \\
\hline $31.00-40.00$ & 56 & $13.30 \%$ \\
\hline $41.00-50.00$ & 47 & $11.20 \%$ \\
\hline $51.00+$ & 63 & $15.0 \%$ \\
\hline Missing & 94 & $22.30 \%$ \\
\hline $\begin{array}{l}\text { Mean } \pm \text { SD } \\
\text { (Min.-Max.) }\end{array}$ & \multicolumn{2}{|l|}{$\begin{array}{l}36 \pm 14 \\
(16-70)\end{array}$} \\
\hline \multicolumn{3}{|l|}{ Gender } \\
\hline Female & 228 & $54.20 \%$ \\
\hline Male & 184 & $43.70 \%$ \\
\hline Missing & 9 & $2.10 \%$ \\
\hline \multicolumn{3}{|l|}{ Educationlevel } \\
\hline Basic school & 13 & $3.10 \%$ \\
\hline High School & 99 & $23.50 \%$ \\
\hline Collage degree & 282 & $67.00 \%$ \\
\hline Post-graduate & 21 & $5.00 \%$ \\
\hline Missing & 6 & $1.40 \%$ \\
\hline \multicolumn{3}{|c|}{ Monthly Income } \\
\hline$<3000$ & 90 & $21.40 \%$ \\
\hline $3000-5000$ & 46 & $10.90 \%$ \\
\hline 5000-7000 & 34 & $8.10 \%$ \\
\hline 7000-10000 & 80 & $19.00 \%$ \\
\hline$>10000$ & 160 & $38.00 \%$ \\
\hline Missing & 11 & $2.60 \%$ \\
\hline \multicolumn{3}{|l|}{ Marital Status } \\
\hline Married & 251 & $59.60 \%$ \\
\hline Un Married & 169 & $40.10 \%$ \\
\hline Missing & 1 & $0.20 \%$ \\
\hline \multicolumn{3}{|l|}{ Employment } \\
\hline Employed & 194 & $46.10 \%$ \\
\hline Un Employed & 216 & $51.30 \%$ \\
\hline Missing & 11 & $2.60 \%$ \\
\hline
\end{tabular}


A total of 360 subjects were included in the study and answered the questionnaire. The age ranged from 16 to 70 years. The mean was 36 and about $8.6 \%$ of subjects were less than 20 years old, $29.7 \%$ of participants were from 2130 years old, $13.3 \%$ were from $31-40 \%$ years old, $11.2 \%$ ranged from $41-50$ years old, $15 \%$ were more than 51 years old and $22.3 \%$ of participants had missing data about age.

The gender distribution showed that $54.2 \%$ of participants were females, $43.7 \%$ were males and $2.1 \%$ had missing data about gender.

The study populationrepresents a highly educated group of people, with $67 \%$ having attended university or college, $23.5 \%$ havingcompleted high school, 5\% having post-graduate degree and 3.1\% completed basicschool and $1.4 \%$ had missing data about education level.

The majority of participants had high level of monthly income (38\%) more than 10.000 SR, followed by $21.4 \%$ of patients had monthly income less than 3000 SR then 19\% had income ranged from 7000-10.000 SR, 10.95\% had an income that ranged from 3000-5000 SR and 8.1\% had an income ranged from 5000-7000 SR.

The marital status showed that the majority of subjects included in the research were (59.6\%) married and $40.1 \%$ were un-married.

The most of subjects were unemployed (51.3\%), and $46.1 \%$ were employed, however only $2.6 \%$ had missing data.

Responses to questions of knowledge assessment questionnaire (Table. 2):

The response of participants to question 1 showed that $76.5 \%$ of patients answered that they had good knowledge about radiation hazards, $58.4 \%$ of subjects answered yes to question 2 as they have knowledge about the importance of radiological assessment demanded by doctors.

As for question 3, 50.6\% of participants had no knowledge about the hazards of excessive and unnecessary use of radiation and $49.4 \%$ answered yes to this question.

Regarding to Q 4, 95\% of subjects said yes to their knowledge about the impact of radiation on pregnant women. But $76.2 \%$ of participants said that the majority of doctors underestimate informing patients about the risks of radiation in Q 5 .

$57.2 \%$ of subjects said that doctors doesn't give them enough protection from radiation and $42.8 \%$ had been given protection from radiation in question 6 . In question 7, 78.9\% of patients had knowledge about the impacts of radiation on children (Figure. 1).

Table 2:- Responses to questions on assessment level of awareness toward radiation exposure risk

\begin{tabular}{|c|c|c|c|}
\hline & No & Yes & $\begin{array}{l}\text { Don't } \\
\text { Know }\end{array}$ \\
\hline Q1: Do you think that the diagnostic radiation has risks? & $\begin{array}{l}99(23.50 \\
\%)\end{array}$ & $\begin{array}{l}322(76.5 \\
0 \%)\end{array}$ & $\begin{array}{l}0 \\
(0.0 \%)\end{array}$ \\
\hline $\begin{array}{l}\text { Q2: Do you think that all radiological scans tests conducted by doctors are } \\
\text { important? }\end{array}$ & $\begin{array}{l}129 \\
(30.60 \%)\end{array}$ & $\begin{array}{l}246 \\
(58.40 \%)\end{array}$ & $\begin{array}{l}46(10.9 \\
0 \%)\end{array}$ \\
\hline $\begin{array}{l}\text { Q3: Do you have knowledge about the damage caused by unnecessary use of } \\
\text { radiology? }\end{array}$ & $\begin{array}{l}213 \\
(50.60 \%)\end{array}$ & $\begin{array}{l}208 \\
(49.40 \%)\end{array}$ & $\begin{array}{l}0 \\
(0.0 \%)\end{array}$ \\
\hline Q4: Do you think that the radiation cause damage to pregnant woman? & $\begin{array}{l}21 \\
(5.00 \%)\end{array}$ & $\begin{array}{l}400 \\
(95.00 \%)\end{array}$ & $\begin{array}{l}0 \\
(0.0 \%)\end{array}$ \\
\hline Q5: Do doctors clarify the impacts of radiological imagingbefore scans? & $\begin{array}{l}321 \\
(76.20 \%)\end{array}$ & $\begin{array}{l}100 \\
(23.80 \%)\end{array}$ & $\begin{array}{l}0 \\
(0.0 \%)\end{array}$ \\
\hline $\begin{array}{l}\text { Q6: Do doctors provide adequate protection for people to avoid excessive } \\
\text { radiation exposure? }\end{array}$ & $\begin{array}{l}241 \\
(57.20 \%)\end{array}$ & $\begin{array}{l}180 \\
(42.80 \%)\end{array}$ & $\begin{array}{l}0 \\
(0.0 \%)\end{array}$ \\
\hline $\begin{array}{l}\text { Q7: Do you think that the excessive exposure of children to radiation may cause } \\
\text { complications in the long term? }\end{array}$ & $\begin{array}{l}89 \\
(21.10 \%)\end{array}$ & $\begin{array}{l}332 \\
(78.90 \%)\end{array}$ & $\begin{array}{l}0 \\
(0.0 \%)\end{array}$ \\
\hline
\end{tabular}




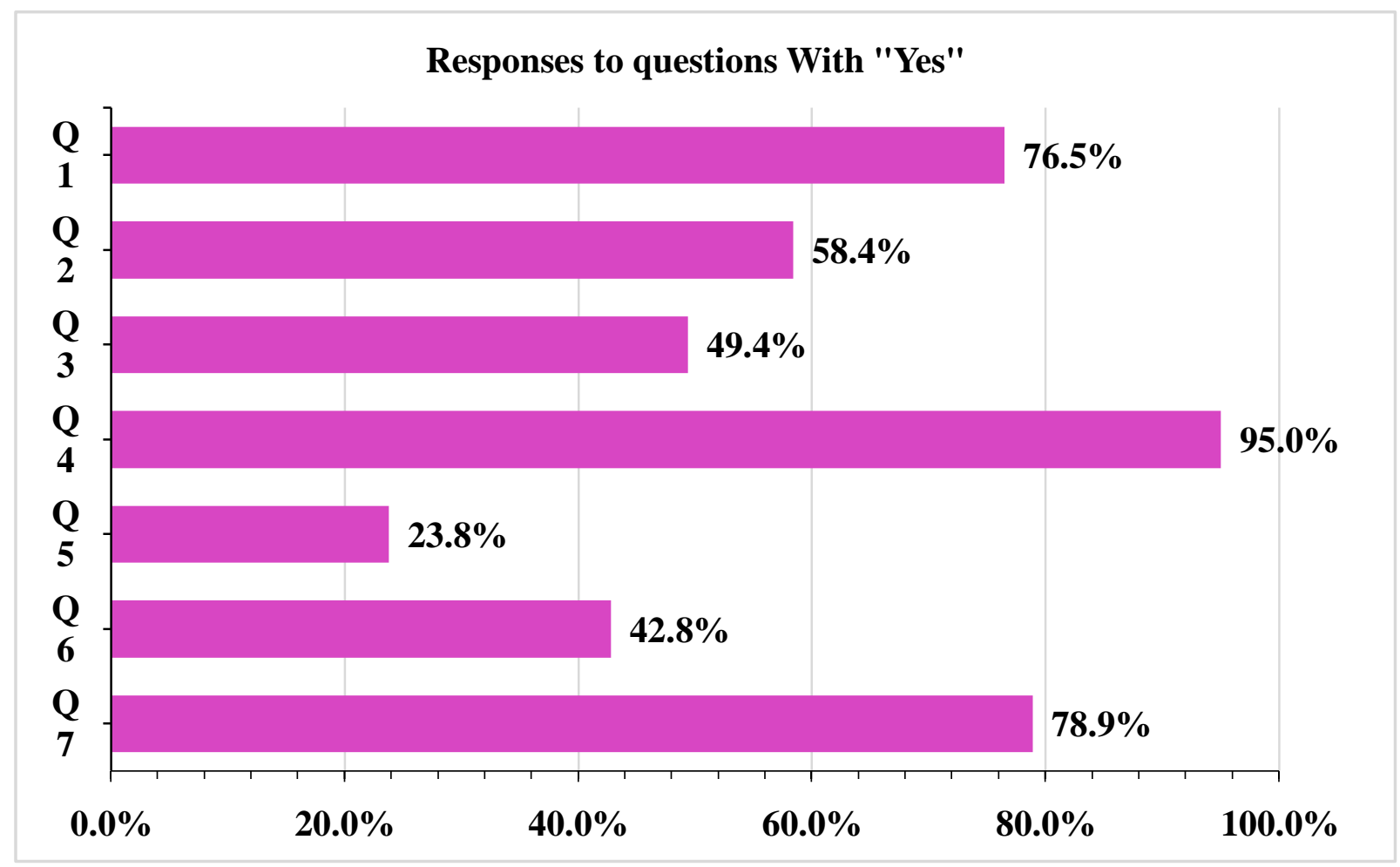

Assessment of knowledge of participants regarding to the risks of exposure to radiation:-

The mean knowledge score was 4.25 for all subjects (Table. 3). The overall mean knowledge score was 4.25 (1.44)(Table. 3).Based on Knowledge score respondents were Categorizing into:Respondents who had good knowledge about radiation exposure hazards corresponded to a score $(\geq$ Mean $+1 \mathrm{SD}=5.69)$ which indicate about $81.2 \%$ knowledge $\%$ and those with bad knowledge corresponded to a score of ( $<$ Mean \pm 1 SD). So, it was found that the majority of (338) (80.29\%)subjects had poor knowledge and only 83 subjects had good knowledge about radiation risks (Figure. 2).

Table 3:- Knowledge of awareness toward radiation exposure risk

\begin{tabular}{|l|l|}
\hline & Knowledge Score \\
\hline Mean \pm SD & $4.25 \pm 1.44$ \\
\hline Min.- Max. & $0-7$ \\
\hline Good Knowledge $(\geq 5.69)$ & $83(19.71 \%)$ \\
\hline Poor knowledge $(<5.69)$ & $338(80.29 \%)$ \\
\hline
\end{tabular}




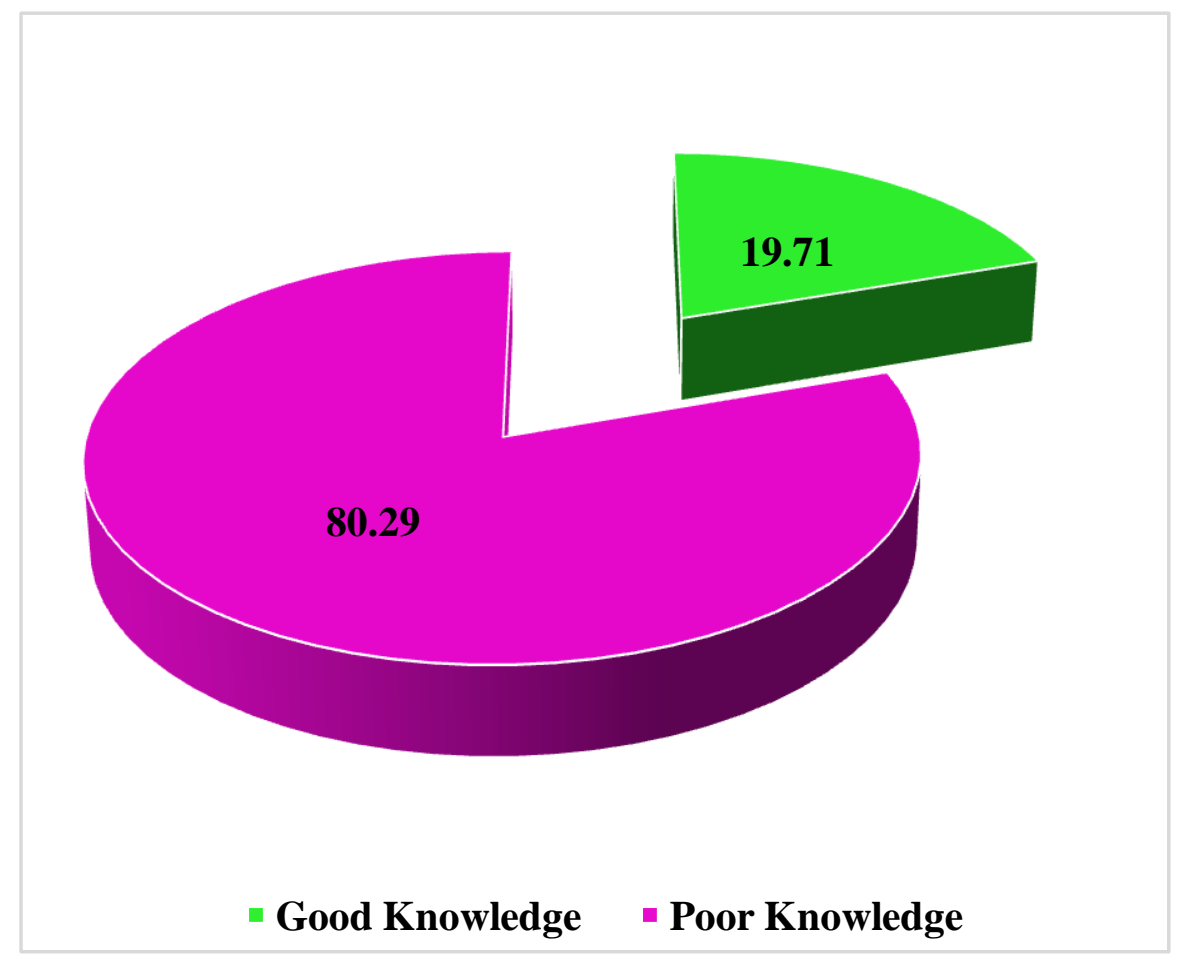

Figure 2:- Respondent's Knowledge about radiation exposure risk

\section{Association between knowledge and demographics of included participants:-}

Univariate logistic regression to study the association between knowledge and participant's demographics showed that, neither age nor other demographic variables showed significant association with being aware of radiation exposure hazard $(\mathrm{P}>0.05)$. However, education level achieved statistical significance $(\mathrm{p}<0.0001)$ association with knowledge as higher education resulted in good levels of radiation exposure risks (Table. 4). Interestingly, it was found that respondents who have completed their college degree have had a higher likelihood to have poor knowledge about radiation exposure hazard with an OR (95\%CI) of 8.07 (3.11 - 20.94) when compared with those who get higher post-graduate degree (Master of $\mathrm{PhD}$ ). Nearly the same difference was found in respondents, who have completed either high school or lower, with \% of poor knowledge about $(80.4 \%)$ when compared with individuals with high post graduate degrees (Figure. 3).

Table. 4:- Univariate logistic regression model for association between radiation knowledge and socio-demographic

\begin{tabular}{|l|l|l|l|l|}
\hline & $\begin{array}{l}\text { Good Knowledge } \\
(\mathbf{n = 8 3})\end{array}$ & $\begin{array}{l}\text { Poor } \\
\text { Knowledge } \\
(\mathbf{n = 3 3 8})\end{array}$ & $\begin{array}{l}\text { OR } \\
(95 \% \mathrm{CI})\end{array}$ & P-value \\
\hline Age & & & & \\
\hline$<=\mathbf{2 0 . 0 0}$ & $5(13.9 \%)$ & $31(86.1 \%)$ & 1 & 0.434 \\
\hline $\mathbf{2 1 . 0 0}-\mathbf{3 0 . 0 0}$ & $30(24.0 \%)$ & $95(76.0 \%)$ & $0.51(0.18-1.43)$ & 0.201 \\
\hline $\mathbf{3 1 . 0 0}-\mathbf{4 0 . 0 0}$ & $8(14.3 \%)$ & $48(85.7 \%)$ & $0.97(0.29-3.23)$ & 0.957 \\
\hline $\mathbf{4 1 . 0 0}-\mathbf{5 0 . 0 0}$ & $9(19.1 \%)$ & $38(80.9 \%)$ & $0.68(0.21-2.24)$ & 0.527 \\
\hline $\mathbf{5 1 . 0 0 +}$ & $10(15.9 \%)$ & $53(84.1 \%)$ & $0.86(0.27-2.73)$ & 0.791 \\
\hline Gender & & & & 0.115 \\
\hline Female & $39(17.1 \%)$ & $189(82.9 \%)$ & 1 & 0.12 \\
\hline Male & $43(23.4 \%)$ & $141(76.6 \%)$ & $0.68(0.42-1.1)$ & \\
\hline
\end{tabular}




\begin{tabular}{|c|c|c|c|c|}
\hline \multicolumn{5}{|l|}{ Education Level } \\
\hline High & $14(66.7 \%)$ & $7(33.3 \%)$ & 1 & $<0.0001$ \\
\hline Intermediate & $56(19.9 \%)$ & $226(80.1 \%)$ & $8.07(3.11-20.94)$ & $<0.0001$ \\
\hline Low & $22(19.6 \%)$ & $90(80.4 \%)$ & $8.18(2.95-22.69)$ & $<0.0001$ \\
\hline \multicolumn{5}{|c|}{ Monthly Income (SR) } \\
\hline$>10,000 \mathrm{SR}$ & $31(19.4 \%)$ & $129(80.6 \%)$ & 1 & 0.68 \\
\hline 3000-10000 SR & $34(21.3 \%)$ & $126(78.8 \%)$ & $0.89(0.52-1.54)$ & 0.677 \\
\hline$<3000 \mathrm{SR}$ & $15(16.7 \%)$ & $75(83.3 \%)$ & $1.2(0.61-2.37)$ & 0.596 \\
\hline \multicolumn{5}{|l|}{ Marital Status } \\
\hline Married & $51(20.3 \%)$ & $200(79.7 \%)$ & 1 & \multirow[t]{2}{*}{0.727} \\
\hline Un Married & $32(18.9 \%)$ & $137(81.1 \%)$ & $1.09(0.67-1.79)$ & \\
\hline \multicolumn{5}{|l|}{ Employment } \\
\hline Employed & $42(21.6 \%)$ & $152(78.4 \%)$ & 1 & \multirow[t]{2}{*}{0.429} \\
\hline Un Employed & $40(18.5 \%)$ & $176(81.5 \%)$ & $1.22(0.75-1.97)$ & \\
\hline
\end{tabular}

OR: Odds ratio, CI: Confidence Interval

Age (21.00 - 30.00)

Age (31.00 - 40.00)

Age (41.00 - 50.00)

Age (51.00+)

Gender (Male)

Education (Intermediate)

Education (Low)

Monthly Income (3000-10000) SR

Monthly Income (<3000) SR

Marital Status (Unmarried)

Employment (Unemployed)

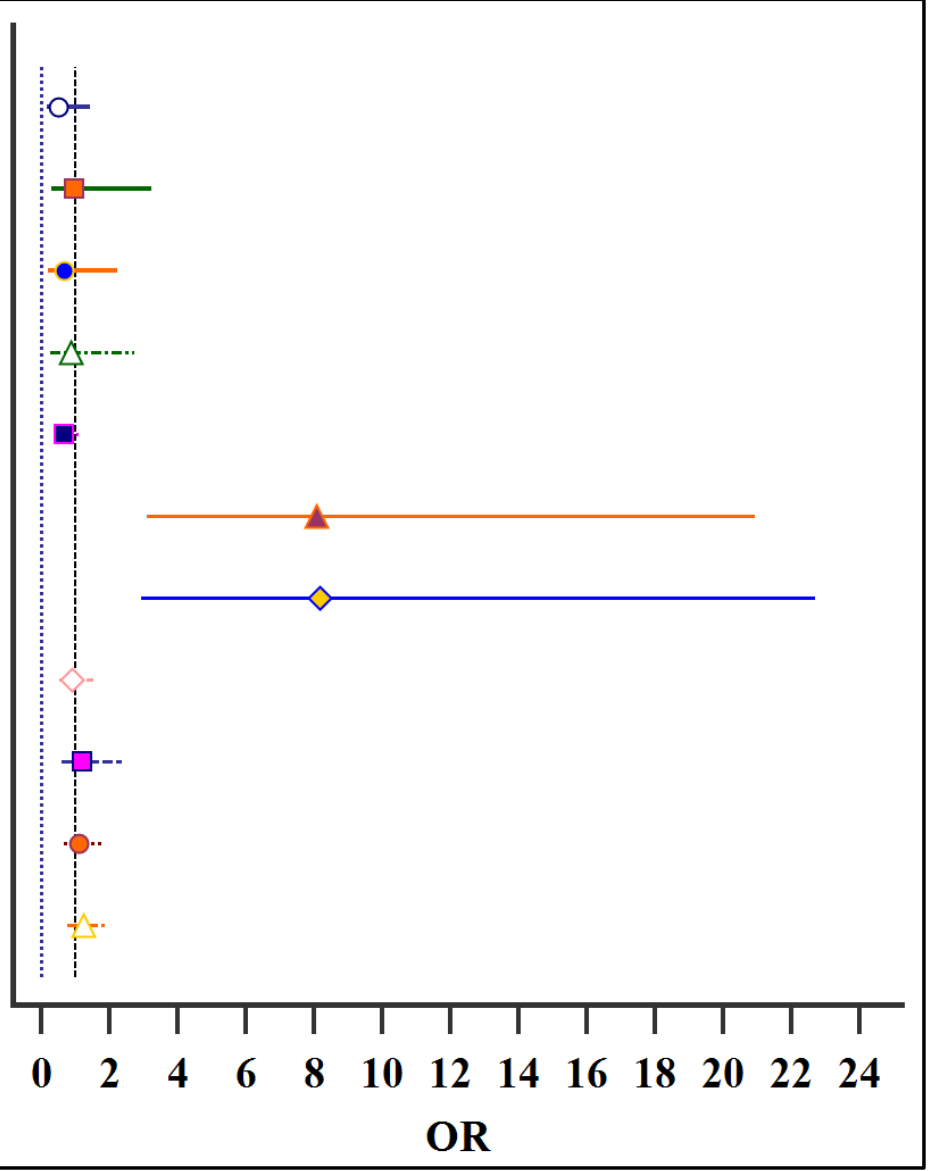

\begin{tabular}{|c|c|}
\hline \multicolumn{2}{|l|}{ Budget } \\
\hline Item & Price \\
\hline Transportations & $700 \mathrm{SR}$ \\
\hline Paper work & $800 \mathrm{SR}$ \\
\hline Software programs & $2000 \mathrm{SR}$ \\
\hline Books & 1000SR \\
\hline Stationaries & $1000 S R$ \\
\hline
\end{tabular}


Work plan

\begin{tabular}{|l|l|}
\hline Tasks in the work plan & Time period \\
\hline Literature review & 2 Months \\
\hline Preparation for data collection & 1 Months \\
\hline Data collection & 3 Months \\
\hline Statistical analysis & 1 Months \\
\hline Discussion of results & 2 months \\
\hline Writing an abstract & 1 months \\
\hline
\end{tabular}

\section{References:-}

1. Thomas KE, Parnell-Parmley JE, Haidar S, Moineddin R, Charkot E, BenDavid G, et al.Assessment of radiation dose awareness among pediatricians. Pediatric radiology. 2006;36(8):823-32.

2. Christodouleas JP, Forrest RD, Ainsley CG, Tochner Z, Hahn SM, Glatstein E.Short-term and long-term health risks of nuclear-power-plant accidents. The New England journal of medicine. 2011;364(24):2334-41.

3. Linet MS, Slovis TL, Miller DL, Kleinerman R, Lee C, Rajaraman P, et al.Cancer risks associated with external radiation from diagnostic imaging procedures. CA Cancer J Clin. 2012;62(2):75-100.

4. Smith-Bindman R.Is computed tomography safe. The New England journal of medicine. 2010;363(1):1-4.

5. Borhani P, MOHAMMAD AS.EVALUATION OF RADIOLOGY PERSONNEL PRACTICE OF KERMAN UNIVERSITY OF MEDICAL SCIENCES HOSPITALS. Med J Hormozgan Univ. 2003;6(4):51-58.

6. Kanda R, Tsuji S, Yonehara H.Perceived risk of nuclear power and other risks during the last 25 years in Japan. Health physics. 2012;102(4):384-90.

7. Perko T.Radiation risk perception: a discrepancy between the experts and the general population. Journal of environmental radioactivity. 2014;133:86-91.

8. Poortinga W, Cox P, Pidgeon NF.The perceived health risks of indoor radon gas and overhead powerlines: a comparative multilevel approach. Risk analysis : an official publication of the Society for Risk Analysis. 2008;28(1):235-48.

9. Baerlocher MO, Detsky AS.Discussing radiation risks associated with CT scans with patients. Jama. 2010;304(19):2170-1.

10. Fazel R, Krumholz HM, Wang Y, Ross JS, Chen J, Ting HH, et al.Exposure to low-dose ionizing radiation from medical imaging procedures. The New England journal of medicine. 2009;361(9):849-57.

11. Brenner DJ, Hall EJ.Computed tomography--an increasing source of radiation exposure. The New England journal of medicine. 2007;357(22):2277-84.

12. Broder J, Fordham LA, Warshauer DM.Increasing utilization of computed tomography in the pediatric emergency department, 2000-2006. Emergency radiology. 2007;14(4):227-32.

13. Golding SJ, Shrimpton PC.Commentary. Radiation dose in CT: are we meeting the challenge? Br J Radiol. 2002;75(889):1-4.

14. Radiation UNSCotEoA. Sources and effects of ionizing radiation: sources: United Nations Publications; 2000.

15. Düzeyleri RKKB, Çalışması KBA.Knowledge About Ionizing Radiation and Radiation Protection Among Patients Awaiting Radiological Examinations: A cross-sectional survey. The Medical Journal of Kocatepe. 2009;10(3):25-32.

16. Fartum AR, Gjertsen JE, Larsen JL.[Patients' knowledge of the effects of X-rays]. Tidsskrift for den Norske laegeforening : tidsskrift for praktisk medicin, ny raekke. 2000;120(28):3427-8.

17. Zhou GZ, Wong DD, Nguyen LK, Mendelson RM.Student and intern awareness of ionising radiation exposure from common diagnostic imaging procedures. Journal of medical imaging and radiation oncology. 2010;54(1):17-23.

18. Karsli T, Kalra MK, Self JL, Rosenfeld JA, Butler S, Simoneaux S. What physicians think about the need for informed consent for communicating the risk of cancer from low-dose radiation. Pediatric radiology. 2009;39(9):917-25.

19. Roche A.[Radiation protection of patients in interventional radiology]. Journal de radiologie. 2010;91(11 Pt 2):1231-5.

20. Takakuwa KM, Estepa AT, Shofer FS.Knowledge and attitudes of emergency department patients regarding radiation risk of CT: Effects of age, sex, race, education, insurance, body mass index, pain, and seriousness of illness. AJR American journal of roentgenology. 2010;195(5):1151-8. 
21. Quinn AD, Taylor CG, Sabharwal T, Sikdar T.Radiation protection awareness in non-radiologists. Br J Radiol. 1997;70:102-6.

22. Brenner D, Elliston C, Hall E, Berdon W.Estimated risks of radiation-induced fatal cancer from pediatric CT. AJR American journal of roentgenology. 2001;176(2):289-96.

23. Almaghrabi N.A Study of Knowledge \& Awareness of Radiation Exposure Risk in Makkah, Saudi Arabia. Int J of Adv Res. 2016;4(7):1852-56.

24. http://www.calculator.net/sample-sizecalculator $\cdot$ html type $=1 \& \mathrm{cl}=95 \& \mathrm{ci}=5 \& \mathrm{ps}=3 \% 2 \mathrm{C} 976 \% 2 \mathrm{C} 000 \& \mathrm{x}=37 \& \mathrm{y}=6$.

25. 50 SY.Central Department Of Statistics \& Information. 2014. 